\title{
CENTROS HISTÓRICOS - MERCANTILIZAÇÃO E TERRITORIALIDADES DO PATRIMÔNIO CULTURAL URBANO
}

\author{
MARIA TEREZA D. PAES-Luchiari \\ Universidade Estadual de Campinas
}

\section{Introdução}

Uma das novas expressões da segregação sócio-espacial no espaço urbano ocorre com a refuncionalização ${ }^{I}$ de patrimônios edificados, sobretudo nos Centros Históricos de cidades atrativas turisticamente. Esta forma de intervenção urbana, definida por meio do acesso às localizações privilegiadas, mediada pelo mercado imobiliário e reproduzida a partir de uma verticalidade que impõe a espetacularização das paisagens, pode ser melhor entendida quando analisamos as políticas de redesenvolvimento ${ }^{2}$ das áreas centrais, antes abandonadas à deterioração, e hoje disputadas pelas atividades mais nobres do comércio.

Estas novas territorialidades urbanas centrais, ao se apropriarem das formas que encerram longos processos de representação social, provocam rupturas na identidade coletiva local e subvertem o caráter público desses bens históricos. Como exemplo podemos citar os projetos de revitalização dos centros históricos de muitas capitais, sobretudo do Nordeste brasileiro, onde as populações locais mais pobres foram desapropriadas de suas antigas territorialidades para dar lugar a centros culturais, restaurantes, bares, cafés, shoppings, hotéis, casas de espetáculos, lojas de souvenirs , ateliês, acessíveis apenas às populações de alto poder aquisitivo. Muitas cidades

\footnotetext{
${ }^{1}$ Neste texto o termo refuncionalização será utilizado para indicar inúmeros projetos de renovação urbana denominados por revitalização, gentrificação, requalificação, enobrecimento, entre outros. Tais termos têm se apresentado como transitórios em seu uso, contraditórios em sua concepção, ou já foram devidamente criticados por inúmeros autores pelo seu uso incorreto, ao passo que o processo de refuncionalização das formas urbanas se estende a todos eles.

${ }^{2}$ Sobre esse conceito ver Featherstone (1995).
} 
brasileiras descobriram, na refuncionalização de suas formas pretéritas, novos usos sociais que agregam valor econômico ao patrimônio cultural edificado. Como a eleição de um patrimônio cultural é sempre um processo socialmente seletivo, é importante desvelar as territorialidades humanas que estão sendo inseridas ou excluídas neste processo, buscando entender a estrutura social que está sendo reproduzida nestas formas urbanas valorizadas e, também, nos defender da fetichização da paisagem.

Inicialmente buscamos situar as tendências contemporâneas que transformaram as cidades, em sua totalidade ou aos fragmentos, em mercadorias vendáveis no mercado global. As concepções de cidade-espetáculo (SÁNCHEZ, 2003) ou cidade-empresa (HARVEY, 1996; VAINER, 2000; BORJA \& CASTELLS, 1997) enfraqueceram o planejamento urbano e regional como empreendimento do Estado, e fortaleceram o planejamento estratégico, mais favorável às empresas.

Em seguida, trazemos à reflexão o conceito de territorialidade como categoria analítica auxiliar na identificação e interpretação dos processos de segregação sócioespacial que vêm ocorrendo em inúmeras áreas centrais urbanas, objetos de intervenções planejadas, motivadas pela refuncionalização de patrimônios históricos edificados.

Enquanto o gerenciamento político e empresarial destituiu antigas populações e territorialidades, novas territorialidades estão emergindo nestas áreas refuncionalizadas que tiveram restauradas as formas tangíveis do patrimônio, mas excluíram os conteúdos sociais indesejáveis - aqueles que não podem ter acesso como cidadãos a estes espaços públicos, transformados em mercadorias acessíveis apenas ao poder de compra das práticas sociais de consumo cultural.

Para melhor refletirmos sobre esse processo e suas contradições, é preciso fortalecer o debate e a compreensão em torno desta nova forma de intervenção urbana, de modo a estimular a politização das diferenças (LEITE, 2004:23) e a reinvenção dos centros históricos como espaços públicos.

\section{Racionalidade e simbolismo na lógica espacial da cidade}

As cidades contemporâneas acirram a competição entre si pela captação de recursos. A guerra fiscal, o City Marketing, os grandes empreendimentos ou a organização de grandes eventos, a organização do setor turístico; várias são as estratégias que as cidades adotam para se fortalecerem como pólo de atração de capitais.

No Brasil, na América Latina, e nos países de industrialização tardia, de maneira geral, esse processo é mais recente e está associado, sobretudo, a valorização turística das cidades a partir dos anos 1990. Em inúmeras cidades da Europa e dos Estados Unidos, esse processo ganha força nos anos 1970, com a retomada das áreas abandonadas pela descentralização industrial, e incorporadas pelo capital privado sob 
a tutela da normatização territorial e pelos incentivos dos gestores urbanos.

O centro das cidades, objeto importante deste processo, é um patrimônio que se constituiu pelo seu papel estruturador das primeiras formas e funções urbanas na criação das cidades, e pela sua vitalidade permanente no decorrer da história. A vitalidade e o movimento presentes nas suas formas-conteúdo (SANTOS, 1996) são da própria natureza dos centros urbanos; por isso neles encontramos a convivência de uma diversidade de formas e funções, pretéritas e presentes, de signos e significados que ganharam ou perderam a importância social no decorrer do tempo. Os conflitos de interesse entre a produção, os serviços e a necessidade de moradias, e entre os valores de uso e os valores de troca das edificações tornam mais evidentes as contradições da transformação da própria cidade em mercadoria.

A sucessão do tempo na dinâmica das áreas centrais urbanas permanece como memória nas edificações e estruturas remanescentes. As rugosidades dos centros que sustentaram a sociabilidade das elites agrárias, com as suas segundas residências, dos centros que polarizaram serviços em redes hierárquicas de cidades, dos centros industriais insalubres e apinhados por habitações miseráveis, dos centros degradados pelo abandono da descentralização industrial, até mesmo dos centros de decisão contemporâneos, símbolos do capital financeiro, dos serviços sofisticados, das elites e da expulsão das populações pobres, materializam o tempo em paisagens urbanas atuais e remanescentes. Todos esses processos sócio-espaciais vão deixando as suas marcas, mesmo aqueles centros que passaram por extensos projetos de modernização e remodelação urbana, expressam concepções que marcaram a organização sócioespacial urbana e contribuíram para que o centro permanecesse como o lugar da diversidade das formas e dos conteúdos históricos da cidade.

A força desta produção social do espaço urbano muitas vezes reside no fato desta parcela da cidade ter representado a cidade toda, em longos períodos da história (SANTOS, 1965:30). Mas o centro de uma cidade não é auto-explicativo; as suas formas, os seus edifícios, a sua dinâmica social refletem as relações locais, regionais, nacionais e internacionais que o condicionam em cada período. Segundo Santos (1965:29): "O centro de uma cidade é, pois, o teatro dessa luta de tendências. Sua síntese se manifesta pela criação de uma paisagem".

As estruturas do passado que permanecem, somadas a própria morfologia do sítio, podem oferecer alguma resistência às influências contemporâneas - sobretudo nos sítios ou conjuntos paisagísticos tombados que ficam condicionados a uma legislação restritiva ao uso e a mudança (limitação de gabarito, por exemplo) -, mas são as forças do presente que se impõem nos centros das cidades. $\mathrm{E}$ quando esta nova dinâmica incorpora novos usos à paisagem, sem imprimir mudanças nas formas, inúmeros processos de refuncionalização podem ocorrer.

Ao refletirmos sobre as concepções que definiram os centros das cidades é importante destacar que a "passagem de um modelo para o outro" (REIS FILHO, 2001:140) reflete os processos mais amplos dos paradigmas produtivos, das mudanças 
culturais e das lógicas espaciais estruturadas pela sociedade.

A cidade capitalista, por exemplo, com a intensificação da divisão territorial do trabalho, ao mesmo tempo em que passa a concentrar mais atividades, ganha novas centralidades. Em seguida, sob a influência do modelo fordista de produção, a concepção modernista recorta a cidade em zonas funcionais de trabalho, serviços, moradia e lazer, gerando múltiplas centralidades conectadas pelas vias de transporte, sobretudo destinadas para o automóvel, ou transporte individual. Os velhos centros perdem, nesse momento, o seu papel de multiplicidade, oủ seja, de integração das funções (ASCHER, 2001:63).

Após um período de obsolescência das áreas centrais tradicionais, processo que ocorreu em inúmeras cidades industriais de países ricos e pobres, estas áreas vão atrair novamente os interesses do capital, seja pelas infra-estruturas instaladas, pela posição estratégica na malha urbana, ou pela possibilidade de agregar valor econômico ao patrimônio arquitetônico que ficou preservado - muitas vezes pelo próprio abandono ou por passarem a viver à margem das concepções mais progressistas de cidade. Além disso, a partir dos anos 1970 o espaço urbano-regional passa a ser estratégico para a economia. Não que não fosse antes, mas, a partir desse momento é deliberadamente transformado em ferramenta - para a ação econômica - e produto - para o mercado.

Iniciativas públicas e privadas se associam nessa concepção de novas estratégias espaciais para a reincorporação de áreas urbanas degradadas. Para Borja (2001:71):

A criação elou reconversão de centros urbanos supõe uma poderosa iniciativa pública (recuperação de áreas obsoletas, atuações infra-estruturais de acessibilidade, desapropriações, equipamentos públicos atrativos ou de prestígio etc.) que dinamizem a inversão privada

Nas tendências do urbanismo contemporâneo, sobretudo naquelas marcadas pelas concepções do planejamento estratégico ${ }^{1}$, os projetos de refuncionalização de extensas áreas urbanas, com patrimônio histórico edificado, podem ganhar várias denominações. Para os arquitetos e urbanistas a requalificação urbana não é a simples revitalização das formas - termo muito criticado por pressupor que antes da intervenção da renovação urbana, não há vida nessas áreas, o que vai de encontro aos centros ocupados por classes populares. Para estes, a requalificação prevê estratégias de inclusão social, respeitando os usos tradicionais das populações locais, e o direito destas à propriedade da terra e à moradia.

Contudo, inúmeros projetos de requalificação urbana têm sido responsáveis pela expulsão das populações locais; seja diretamente, pela introdução de novos usos às

\footnotetext{
${ }^{3}$ Sobre planejamento estratégico ver especialmente: Borja \& Casttels (1997), Borja (2001).
} 
edificações, muitas vezes seletivos e inacessíveis às populações de baixa renda; seja indiretamente, pela valorização econômica atribuída ao solo urbano, o que leva as populações mais pobres a venderem os seus imóveis, evitando o pagamento dos impostos que se elevam com a valorização urbana, ou mesmo buscando a obtenção de lucros e migrando para áreas periféricas menos valorizadas, o que desloca a visibilidade da segregação sócio-espacial.

Os centros históricos e as áreas portuárias, rugosidades abandonadas e degradadas da cidade industrial capitalista, são exemplos emblemáticos desse processo (DODSON \& KILIAN, 2001). O modelo de Barcelona, inspirado na "cidade-empreendimento de formato americano" (ARANTES, 2000:51), e reproduzido quase como uma receita de urbanismo em inúmeras cidades pelo mundo, representa, para muitos estudiosos, um divisor de águas entre o planejamento urbano e regional tradicional, concebido pela racionalidade territorial sob o controle do Estado, e o planejamento estratégico concepção que toma a cidade aos fragmentos, comandada pela lógica empresarial neoliberal. Barcelona capitalizou os recursos financeiros que foram atraídos pelos Jogos Olímpicos em 1992, e executou um grande projeto de renovação urbana na área portuária abandonada, fazendo desta um cenário valorizado para novas formas de lazer, de habitação e de consumo cultural.

A fórmula dessa nova estratégia urbanística abusa do City Marketing ${ }^{2}$, da exploração dos bens culturais, da potencialização dos indicadores de qualidade de vida, das intervenções urbanas pontuais mas espetacularizadas. Ao recuperar ou mesmo produzir o capital simbólico que dá sentido a venda das cidades nos circuitos culturais internacionais, a cidade passa a construir sua própria marca, carregada de positividade.

O Plano que se seguiu, "Barcelona 2000", buscou recuperar uma concepção mais abrangente do planejamento, preocupando-se com a infra-estrutura, com o sistema viário, com o patrimônio arquitetônico e com os espaços públicos. Mas, de qualquer forma, a ideologia alimentadora da concepção deste novo urbanismo que coloca a cultura no centro da economia (ou vice-versa?) não nos deixa esquecer do que Arantes (2000, p. 15) denominou de o "reencontro glamouroso entre Cultura (urbana ou não) e Capital", e Peet (1997) de "capitalismo semiótico".

Sejam os projetos de requalificação, renovação, gentrificação, revitalização, enobrecimento ou outra definição qualquer, o que se quer nominar é a recuperação de áreas urbanas degradadas ou abandonadas pela cultura industrial, que possam trazer de volta aos centros, aos portos, às vilas operárias ou outras áreas refuncionalizadas, as classes sociais com maior poder aquisitivo e capital cultural mais valorizado. Por isso, nesse momento, a cultura se torna mercadoria e moeda de troca que impregna os objetos, os bens culturais e a própria paisagem urbana - reflexão que concorda com Arantes (2000:31), quando esta afirma:

\footnotetext{
${ }^{4}$ Sobre esse tema ver especialmente Sánchez (2003).
} 
Rentabilidade e patrimônio arquitetônico-cultural se dão as mãos, nesse processo de 'revalorização urbana' - sempre, evidentemente, em nome de um alegado civismo (como contestar?...). E para entrar neste universo dos negócios, a senha mais prestigiosa - a que ponto chegamos! (de sofisticação?) - é a Cultura. Essa a nova grife do mundo 'fashion', da sociedade afluente dos altos serviços a que todos aspiram.

Esse casamento entre cultura urbana e capital imobiliário já havia dado certo no processo de gentrificação ${ }^{l}$ dos lofts no bairro do SoHo, em Nova York, nos anos 1970. A estratégia imobiliária, neste caso, foi incorporar as antigas estruturas industriais abandonadas (extensos galpões de manufaturas), convertendo-as em edificações residenciais sofisticadas, em galerias de arte ou de serviços para o consumo cultural, de modo que se expulsou os antigos moradores e se acolheu uma burguesia associada às artes e à cultura.

Essa apropriação dos gostos culturais, dos estilos da cultura de vanguarda e dos valores simbólicos das elites, proporciona o controle das territorialidades urbanas por meio da cultura, assim como legitima a fetichização da paisagem revitalizada e a estetização do poder que controla a reprodução e a exclusão social no território.

Para Harvey (1989:89), a espetacularização urbana se inicia nos Estados Unidos, na década de 1960, em Baltimore. Após inúmeras manifestações dos movimentos sociais da contra-cultura e de oposições políticas, um esforço de renovação urbana foi idealizado por um grupo de políticos, empresários e profissionais para retomar na ordem da cidade, a partir, sobretudo, da reincorporação do centro, a ordem social perdida. Uma das estratégias foi a organização de uma grande feira, a Baltimore City Fair, que passou a promover a venda da identidade e da diversidade étnica; e a construção de uma estrutura de eventos e lazer no centro da cidade que, segundo Harvey (1989:90), passou a receber mais visitantes que a Disneylândia.

Esse projeto se distanciou da racionalidade da arquitetura modernista, mas acirrou as estratégias de segregação urbana e exclusão social. Essas novas formas e estruturas, inseridas no tecido urbano, são mais fetichizadas do que possam parecer no efeito das luzes e do mise-en-scène. Essa nova forma de apropriação da cidade corrói a concepção de planejamento racional para dar lugar a um mosaico de signos e imagens que dissolve a hierarquia bem comportada da estratificação social por classe e ocupação, e a substitui por uma rede caótica de relações onde o "individualismo" e o "empreendimentismo" dão o tom.

A verdade é que as manifestações, os eventos e as formas valorizadas culturalmente foram capturados pela nova racionalidade da economia urbana: a identidade social

\footnotetext{
${ }^{5}$ Gentrificação e enobrecimento: termos utilizados sobretudo nos Estados Unidos e na Inglaterra dos anos 1970, criticados por diversos autores, e definidos como intervenções para a recuperação da vida urbana nas áreas centrais, ou volta dos grupos sociais mais ricos para essas áreas.
} 
proporcionada pelo lugar somou-se a espacialidade estetizada, fragmentada, superficial e globalizada da cidade-mercadoria.

Nesse sentido, é importante ressaltar que a arquitetura pós-moderna, ao se colocar como alternativa a racionalização dos espaços concebida pela arquitetura modernista, escorrega em inúmeras contradições. Enquanto a concepção pós-moderna valoriza a diferença, os múltiplos contextos sociais e a memória histórica, ela, ao mesmo tempo, utiliza-se de um tradicionalismo superficial das formas a partir de um total liberalismo de estilos. Um ecletismo que fez da disponibilidade de formas construídas na história uma "bricolagem". É que apesar do momento de inflexão, responsável por transformações drásticas em diferentes esferas da vida nos anos 1970, entre o "simbolizar" da pós-modernidade e o "estruturar" da modernidade muitas semelhanças permanecem nessa produção social contraditória do espaço urbano.

Mas inúmeras cidades vão seguir o modelo da espetacularização urbana, agregando às paisagens o valor econômico agora sustentado pelo discurso ambiental, cultural e da qualidade de vida. Dos países centrais aos periféricos, inúmeras cidades procuram copiar a fórmula, ainda que nem todos adotem o planejamento estratégico, como é o caso de Paris e Berlim. Para Arantes (2000:66), ainda nessas cidades:

Não falta nenhum dos ingredientes do atual modo de fazer cidade, além do mais na escala gigantesca de uma capital com ambições imperiais: megaprojetos emblemáticos; urbanismo acintosamente corporativo, nenhuma grande marca global está ausente; gentrificações se alastrando por todo o canto; exibição arquitetônica em grande estilo; parques museográficos; salas de espetáculo agrupadas em complexos 'multiservice' de aparato e muita, muita animação cultural 24 horas. Ou seja, continuamos na mesma.

A autora se pergunta: "como pudemos chegar a esse ponto?", questionando o que ela define como "culturalismo de mercado" capaz de alimentar "a novíssima flexibilidade requerida pelo mundo 'produtivo' dos negócios, que não por acaso se organizam em redes comunicacionais", estruturadas pelo o que a autora denomina de "um pensamento único de cidade" (ARANTES, 2000:67).

Hall (2002:415), ao analisar o início da expansão desse modelo nas cidades americanas, afirma: "Suas bases são despudoradamente turísticas". O planejamento convencional que regulamentava o uso do solo havia aberto a guarda para o empreendedor, e as cidades, então, transformaram-se "em máquinas de produzir riqueza" (HALL, 2002:410). E, nesse caso, como afirma Borja (2001:70), equipamentos culturais e turísticos e infra-estruturas econômicas são praticamente sinônimos.

Turismo, patrimônio cultural e qualidade ambiental seriam os novos ingredientes na atribuição de novos sentidos à paisagem urbana.

Estas novas formas da paisagem urbana, espetacularizadas pelo city marketing e pelo turismo, podem nos auxiliar a compreender as ideologias que azeitam a estrutura social dominante, assim como os processos que estão incrustados na dinâmica dessas 
paisagens. Longe de considera-las neutras, ou suportes inertes da ação social, estas paisagens nos enganam pela fetichização de suas formas. Recorrendo a Harvey (1997:51): "É tão tolo negar o papel e o poder de reificação, a capacidade das coisas que criamos de retornar a nós enquanto formas de dominação, como atribuir a tais coisas a capacidade para a ação social".

Retornemos, então, aos Centros Históricos refuncionalizados. A opção dada pela dinamização da atividade turística e pela revalorização do patrimônio histórico edificado, é uma alternativa da economia urbana contemporânea para a reincorporação de áreas degradadas. Mas essa pode ser uma opção efêmera, já que inúmeros projetos de refuncionalização têm padronizado a oferta de conjuntos paisagísticos restaurados, assim como dos serviços da indústria cultural, perdendo, no valor de mercado, o seu atributo original - a peculiaridade da paisagem, do lugar, da cultura, do ambiente -, ou seja, o diferencial que pode servir como atrativo turístico.

Além disso, esses projetos têm deixado de fora os pobres - esse problema urbano que foi realçado pela assepsia social dessas áreas renovadas e pelos outros, como coloca Hall (2002:427), "a ralé urbana, que lá está, massa mal-humorada e inamistosa, à espera do lado de fora dos portões".

Sobretudo nos países pobres, a pobreza é muito visível nas paisagens das áreas centrais (REIS FILHO, 2001:143). Como esconder essa pobreza que incomoda, já que não conseguimos acabar com ela? Melhor envia-la para os seus redutos, para que esta população fique "prisioneira dos seus próprios bairros", enquanto o centro pode se iluminar em um espetáculo digno do olhar internacional. A intencionalidade desses projetos de renovação urbana é clara: utilizar objetos dotados de carga simbólica, culturalmente significativos e iluminados pelas luzes do espetáculo. Embora a imagem de modernidade projetada no território só se revele pela produção simultânea de luz e sombra.

\section{Refuncionalização e novas territorialidades urbanas}

As áreas centrais urbanas, de modo geral, têm sido progressivamente marcadas por uma diferenciação sócio-espacial crescente, delimitando territorialidades distintas e reforçando as dinâmicas de acesso desigual à cidade contemporânea. Devido a dinâmica permanente de uso e ocupação do solo dessas áreas, inúmeras formas, passadas e presentes, revelam a diversidade de usos sociais que ganharam ou perderam o seu papel na configuração sócio-espacial das cidades. Difícil, nesse caso, considerando a dinâmica histórica das áreas centrais das grandes cidades brasileiras, reconhecer a "hegemonia de traços culturais genuinamente próprios e específicos em si, senão combinados, alternados e articulados" (CAMPOS, 2002:38). Nestas áreas ocorre uma luta contínua e permanente entre territorialidades antigas e novas.

Como a territorialidade é uma ferramenta analítica de definição ainda imprecisa na geografia, cabe fazer aqui algumas aproximações. As territorialidades compreendem 
uma forma de comportamento sócio-espacial que tem implicações normativas, onde as relações de poder se projetam também simbolicamente. Esse exercício de poder é viabilizado pela criação de fronteiras (inclusive simbólicas) em determinadas áreas, moldando comportamentos, influenciando e controlando os usos dessas territorialidades.

A territorialidade não é tão somente a escala grande do território; as territorialidades estabelecidas pelas práticas sócio-culturais por meio de demarcação identitária, de intervenções do planejamento ou dos empreendimentos comandados pelo mercado possuem especificidades em relação à concepção tradicional de território em geografia. A categoria território, tão cara à geografia, foi trabalhada sob diferentes recortes na história do pensamento geográfico. De Ratzel a Raffestin, da Geografia Cultural, Humanística à Nova Geografia Cultural o território e a territorialidade humana ganharam estatuto de categoria analítica, fundamental na abordagem do espaço geográfico. Contudo, o recorte político do território, sustentado pelas necessidades efetivas de controle dos Estados-Nação, ganhou a hegemonia nos estudos dos geógrafos que o associaram à Geografia Política e à Geopolítica.

Partindo dos pressupostos que sustentam a abordagem do território, podemos dizer que ele é estabelecido por um recorte político, permeado por estratégias de poder; é delimitado por fronteiras materiais ou simbólicas; é objeto de planejamento ou de uma normatização social, e possui graus de institucionalidade, objetivando uma coesão institucional. "A territorialidade, por sua vez - como afirma Corrêa (1994:241) -, refere-se ao conjunto de práticas e suas expressões materiais e simbólicas capazes de garantirem a apropriação e a permanência de um dado território por um determinado agente social, o Estado, os diferentes grupos sociais e as empresas".

Santos (2000:02), afirma a sua escolha em trabalhar com a noção de território usado, a "totalidade das causas e dos efeitos do processo socioterritorial". Para ele, esta abordagem permite a construção de uma teoria social e de propostas totalizadoras de intervenção socioterritorial; assim como permite, também, o pensamento processual das relações entre o lugar, a formação socioespacial e o mundo. É no jogo dialético entre os agentes hegemônicos da organização do território e aqueles que transformam o território em lugar de sobrevivência cotidiana que Santos reencontra a totalidade na abordagem geográfica. Para ele, "enfoques totalizadores tendem a buscar uma correspondência à unidade do mundo real" (2000:09), abordagem possível, segundo ele, por meio do território usado.

Mas seu recorte predileto sempre foi o político. Assim, mesmo abordando o território usado, e inserindo aí as práticas sociais cotidianas, o enfoque cultural é apenas subentendido. A territorialidade não é desenvolvida por Santos (1999:21) que prefere qualificá-la como saber local:

A territorialidade é um atributo do território ou dos seus ocupantes? Vivo o meu cotidiano no território nacional ou no lugar? Essas perguntas me parecem importantes porque estão ligadas ao que eu chamaria de saber da região em contraposição ao saber do expert internacional. 
As relações de poder manifestas no território sempre foram abordadas, predominantemente, por meio da política dos Estados e, contemporaneamente, pela política das empresas, tendo o território nacional em primeiro plano, até a escala do município. A escala maior, do cotidiano, do espaço vivido, da rua, dos guetos, dos espaços segregados da cidade tem sido objeto dos esforços de uma abordagem, ainda tímida, da Geografia Cultural e de outras ciências sociais como a Sociologia e a Antropologia. Como afirma Souza (1995:81):

Não obstante esta riqueza de situações, não apenas o senso comum, mas também a maior parte da literatura científica, tradicionalmente restringiu o conceito de território à sua forma mais grandiloqüente $e$ carregada de carga ideológica: o território nacional.

Algumas abordagens, contudo, nos permitem conceituar o território associando as relações de poder a ele inerentes à sua substância cultural.

Guattari (1985), por exemplo, analisa o espaço produzido por determinada sociedade como um dado fundamental para a caracterização do poder. Assim, ao contrapor os espaços lisos aos territórios existenciais, aponta para a subjetividade dos constrangimentos espaciais que a ordem capitalista produz. Segundo Guattari (1985:112): “Um espaço liso é um espaço desterritorializado, aonde não há mais os mesmos tipos de circunscrições ou delimitações por emblemas étnicos ou religiosos, por exemplo". Enquanto o alisamento dos espaços leva a destruição dos territórios existenciais, a emergência de territorialidades novas e imprevistas pode representar um exemplo de insubmissão do cotidiano às arquiteturas disciplinares - embora estas mesmas arquiteturas disciplinares possam também organizar novas territorialidades.

É prudente constatar que Guattari não concebe o espaço geográfico enquanto uma categoria abstrata que vai ganhando concretude nos lugares por meio da dinâmica da estrutura social. É como se o espaço liso fosse apenas uma escala menor, e com uma funcionalidade mais imperativa em relação às territorialidades que ele contém, e por isso as submete.

Claude Raffestin (1993) constrói uma análise mais racionalizada e mais rigorosa do território, embora ele também se aproxime de uma abordagem mais política do espaço geográfico. Para ele, os atores sociais territorializam o espaço a partir de uma apropriação concreta ou abstrata, sendo que, no segundo caso esta pode se dar através de uma representação (mapas e cartas, por exemplo). O espaço é anterior às relações de poder que vão dividi-lo transformando-o em territórios. E, neste caso, a diferenciação apresentada não é apenas de escala, mas conceitual. "O espaço é a prisão original, o território é a prisão que os homens constroem para si", nos fala Raffestin (1993:144).

Neste sentido ele complementa que, para um marxista, antes desta "apropriação" o espaço só tem valor de uso, não de troca; o que é discutível, pois o valor de uso já é a atribuição de um valor social, de uma funcionalidade transformadora do espaço. Mesmo não tendo valor de troca, o valor de uso já atribui uma territorialidade ao 
espaço. É baseada nesta lógica que a indústria da construção civil das cidades contemporâneas induz valores de uso para gerar valores de troca.

A territorialidade expressa a intencionalidade de estabelecer relações de poder e alteridade, uma necessidade social de separar identidades. Os sistemas de representação espacial são instrumentos bastante conhecidos na explicação da História; da cartografia moderna ao planejamento territorial muitas representações espaciais foram produzidas para assegurar o controle social. Apesar disto, à lógica racionalizadora de tessituras impostas para a sociedade pelo Estado, ou pelo poder do dinheiro, somamse territorialidades imprevistas que brotam das relações vividas por uma coletividade. A construção de territorialidades, que emergem nos lugares, fortalece o sentimento de pertencimento e de exclusividade legitimados pela apropriação e pelo uso. E nesta análise entre tessituras impostas e territorialidades vividas, Raffestin e Guattari concordam.

Desde as organizações mais elementares até as mais complexas, impera a necessidade de organizar as territorialidades e promover distâncias e acessibilidades. A ordenação dos territórios reflete a ordenação da estrutura internalizada da própria sociedade. Apesar da idéia implícita de limite, este pode ser representado por valores expressos na normatização das distâncias sociais, culturais, econômicas, étnicas, religiosas, entre outras.

Territorialidades são formas de expressão de poder que classificam e hierarquizam estratégias de inclusão e exclusão social, normatizando comportamentos, controlando os acessos, homogeneizando ou padronizando bens materiais ou simbólicos a serem aceitos pelos membros do grupo que a compõem. Criam identificação simbólica para determinados grupos sociais, e são excludentes por natureza pois, ao contrário do território usado de Santos (2000), que inclui a diversidade conflitiva dos usos variados, a territorialidade estabelece as formas de expressão de um grupo social hegemônico - seja na esfera cultural, política ou econômica. Exemplos de territorialidades exclusivas podem ser encontrados nos condomínios fechados horizontais, modelo de autosegregação das classes médias e elites urbanas contemporâneas; nos mega-projetos turísticos (resorts, lodges, complexos hoteleiros, parques temáticos), nos enclaves fortificados dos centros urbanos, analisados por Caldeira (2000), mas também nas favelas dos morros do Rio de Janeiro, nas edificações abandonadas e apropriadas por grupos da cultura popular, enfim, em inúmeras apropriações consentidas, normatizadas, regulamentadas ou não, mas que expressam o exercício de poder de um grupo cultural ou econômico que, ao afirmar uma identidade, busca impor a sua legitimidade sobre uma parcela do território.

O problema é que a territorialidade, hoje, não é necessariamente uma construção cultural legítima de um grupo social em relação ao seu meio. Ela é, muitas vezes, artificial, precede ao valor de uso e é vendida, a posteriori, como bem distintivo de consumo de classes sociais identificadas anteriormente pelo mercado. É dessa forma que são construídas, organizadas e vendidas as territorialidades associadas à "vida 
em comunidade" de condomínios fechados, ao retorno à natureza em um hotel de selva ou em um resort, aos produtos culturais em um centro histórico revitalizado.

As territorialidades urbanas contemporâneas, incorporadas pelas estratégias do mercado, são produtos comercializados para consumidores pré-selecionados. No espaço urbano, as territorialidades são cada vez mais definidas através do acesso às localizações privilegiadas, mediado pelo mercado imobiliário.

Esta apropriação dos bens culturais está alicerçada na atribuição de valor econômico aos lugares, que seleciona um conjunto de formas e as torna atrativas para o consumo cultural. Como assinala Featherstone (1995:140),

(...) a cidade pós-moderna, portanto, está muito mais consciente de sua própria dimensão imagética e cultural: ela é um centro de consumo cultural, tanto quanto de consumo geral, e este (...) não pode ser desvinculado dos signos e imaginários culturais, de modo que os próprios estilos de vida urbanos, a vida cotidiana e as atividades de lazer são influenciadas, em graus variados, pelas tendências simulacionais pósmodernas.

\section{Considerações finais}

Dentro desse contexto, os centros históricos das cidades mais adensadas abandonam o caráter público dos seus bens patrimoniais para coloca-los no mercado. Embora seja positiva a iniciativa destes projetos em transformar muitos espaços privados (mercados, ruas, galerias, jardins, igrejas) em espaços coletivos, o que tem ocorrido nas cidades brasileiras é a conversão dos tradicionais espaços públicos em espaços coletivos privados, acessíveis apenas mediante o poder aquisitivo de determinados grupos sociais.

Logo, percebemos que a produção de novas territorialidades urbanas está profundamente ligada à refuncionalização das áreas centrais. Esse processo tem sido mais visível nas cidades que puderam acumular capital cultural (modo de poder e acumulação baseados na cultura), inclusive sob a forma de patrimônio arquitetônico preservado. E são exatamente essas cidades que vêm sendo objeto dos programas de revalorização das áreas centrais, estabelecendo assim novas territorialidades, no que tange ao público a que se destinam essas refuncionalizações.

Muitas cidades brasileiras, sobretudo capitais, já passaram por esta experiência:

As iniciativas de 'revitalização' seguiram, inicialmente, os preceitos contidos nas cartas patrimoniais, com alcance restrito aos sitios históricos, ou parcelas deles, estimulados por políticas de preservação desenvolvidas ainda na década de 1980. Salvo os casos de cidades históricas, a exemplo de Ouro Preto, onde necessariamente o sítio histórico era praticamente a própria cidade, pouco se atingiu, no sentido de conservar a cidade e sua vida. (MINISTÉRIO DAS CIDADES, 2004:73) 
Apesar da intencionalidade ser a conexão com as redes globais, na maioria dos casos a cidade é vista aos fragmentos, e permanecem com programas restritos de atividades ligadas ao turismo e ao entretenimento. O caso de Recife, por exemplo, contempla principalmente a área do cais, antes degradada, abrigando a zona de prostituição e pensões de alta rotatividade em meio aos prédios históricos deteriorados. Com a revalorização dessa área, os prédios foram restaurados e passaram a abrigar atividades turísticas variadas, como bares e restaurantes de luxo, territorialidades renovadas que disputam espaço e legitimidade social com os grupos-sociais mais populares.

Outro exemplo é o de Salvador, que apesar de ser uma boa referência em termos de restauro, de recuperação da arquitetura colonial, do ponto de vista da sua refuncionalização é segregador, pois a população tradicional do Pelourinho foi expulsa, mudando completamente as características daquele lugar.

Estes e inúmeros outros exemplos ilustram os novos valores de uso que vêm sendo atribuídos ao patrimônio arquitetônico brasileiro e refuncionalizando-os. Nesse sentido, Meneses (1999) afirma que a cidade só será um "bem cultural" quando for "boa para morar", ou seja, para a prática cotidiana de seus habitantes, sem excluir os visitantes. Logo, os projetos de valorização cultural e refuncionalização urbana devem se preocupar também com a infra-estrutura da cidade para sua população: habitação, transporte, saneamento. Para Meneses, alterou-se o valor cognitivo associado ao patrimônio cultural, que hoje reconhece, de forma geral, apenas o feitio e a estética dos objetos, aquilo que está ao alcance de olhares descomprometidos e acostumados a serem bombardeados por informações visuais de conhecimento redutor.

As conseqüências mais enfáticas desse processo são aquelas relacionadas à seletividade social que as novas territorialidades do patrimônio passam a impor. Com isso, a referência e a identidade, o sentimento de pertença ao lugar por parte daqueles que não podem vivenciar o patrimônio se dilui e é suplantado pelo novo padrão de consumo cultural, estritamente ligado à valorização estética e mercadológica do patrimônio.

As contradições entre exclusão e inclusão social, esvaziamento e reabilitação permanecem nos planos que se lançam a resolver as questões-problema das áreas centrais. E certamente não serão as concepções da cidade-empresa que nos mostrarão os valores éticos que devem ser observados nos projetos de renovação urbana: "A instauração da cidade-empresa constitui, em tudo e por tudo, uma negação radical da cidade enquanto espaço político - enquanto polis" (VAINER, 2000:91). Estas novas territorialidades da globalização atingem, nesse momento, países que ainda não estenderam suas infra-estruturas e a equidade social por todo o seu território. Dessa forma, ao tomar estas áreas centrais como guetos do consumo cultural, esses projetos fortalecem ainda mais o processo de modernização fragmentada, e inviabilizam a democratização da urbanidade.

O Ministério das Cidades (2004:75) torna clara essa contradição quando expõe que, enquanto o déficit de moradias para o país gira em torno de 6,5 milhões de 
unidades, estas áreas, muitas vezes ricas em estoques imobiliários, participam entre os 5 milhões de domicílios vagos: "Em Recife e no Rio de Janeiro os imóveis vagos chegam a $18 \%$ do total de domicílios da área urbana. Só na cidade de São Paulo são 400 mil domicílios urbanos vagos, a maioria situada em áreas consolidadas centrais".

A preservação dos Centros Históricos tradicionais deve privilegiar os antigos usos como a habitação, o comércio, os serviços, e estimular novas funções, como o turismo cultural, a fim de torna-lo atraente para que volte a abranger também as atividades mais nobres. Mas não enobrece-lo completamente. A proposta de trazer novos atrativos culturais para atrair novamente a população para o Centro é uma estratégia positiva, mas deve incluir atrativos para os diferentes estratos sociais, evitando um processo de elitização. Além disso, estas estratégias devem estar integradas em uma Política Pública intersetorial, afinal, são estratégias que dialogam com os problemas estruturais da cidade, como: dos transportes, segurança, comércio, habitação, saneamento, enfim, do planejamento territorial.

Cabe lembrar que o Centro sempre foi rico em espaços públicos, passíveis de serem apropriados por diferentes manifestações culturais, políticas, lúdicas. É importante não perder de vista esta característica ao transformar os seus atrativos em bens acessíveis apenas por meio da comercialização, como ocorre na maior parte dos lugares turísticos. A subversão do caráter público dos bens tombados reforça as estratégias de exclusão social do consumo cultural.

A valorização contemporânea do patrimônio tem deslocado os bens culturais tombados das relações sociais construídas localmente, inserindo as cidades na racionalidade global do consumo visual das paisagens enobrecidas para o lazer e para o turismo cultural. Esta inversão põe em risco os preceitos do direito à cidade, à qualidade de vida, e ao direito à memória, indo na contra-mão das possibilidades da esfera cultural transformar-se no vetor de uma apropriação mais democrática da cidade e dos seus bens patrimoniais.

\section{CENTROS HISTÓRICOS - MERCANTILIZAÇÃO E TERRITORIALIDADES DO PATRIMÔNIO CULTURAL URBANO}

Resumo: Este artigo trás à reflexão os processos sócio-espaciais envolvidos nos atuais projetos de refuncionalização urbana, destacando as estratégias de preservação do patrimônio histórico edificado e de reintegração de áreas urbanas abandonadas, sobretudo nos Centros Históricos consolidados pela industrialização. O gerenciamento político e empresarial dessas áreas tem subvertido o caráter público desses bens e fortalecido a imagem das cidades como mercadorias vendáveis no mercado global.

Palavras-chave: Refuncionalização urbana, Centros Históricos, Patrimônio Cultural

\section{HISTORICAL CENTERS - MERCANTILIZATION AND TERRITORIALITIES OF THE URBAN CULTURAL PATRIMONY}


Abstract: This paper aims to contribute to the reflection of the socio-spatial processes involved in the current projects of urban refuntionalization, enhancing the strategies for preservation of the built historical patrimony and the reintegration of the abandoned urban areas, mainly in the historical centers consolidated by industries. The political and business management have subverted the public character of these goods, and strength the image of cities as goods to be sold in the global market.

Keywords: Urban refuntionalization, Historical centers, Cultural Patrimony

\section{BIBLIOGRAFIA}

ASCHER, François .2001. "Metropolização e transformação dos centros das cidades" (pp. 59-68) In: Os centros das metrópoles - reflexões e propostas para a cidade democrática do século XXI, São Paulo: Editora Terceiro Nome/Viva o Centro/Imprensa Oficial.

ARANTES, Otília. 2000. "Uma estratégia fatal: a cultura nas novas gestões urbanas" (pp. 11-74) In: Arantes, O., Vainer, C. e Maricato, E. (Orgs.) A cidade do pensamento único: desmanchando consensos, Rio de Janeiro: Edit. Vozes. BORJA, Jord. 2001. "Urbanização e centralidade" (69-85) In: Os centros das cidades - reflexões e propostas para a cidade democrática do século XXI, São Paulo: Editora Terceiro Nome/Viva o Centro/Imprensa Oficial.

BORJA, J. \& CASTELLS, M. 1997. Local y global. La gestión de las ciudades en la era de la información, United Nations for Human Settlements (Habitat), Madrid: Taurus / Pensamiento.

CAMPOS, H. A. 2002."Refletindo sobre o papel das representações nas territorialidades urbanas: o exemplo da área central de Recife." In: Geousp. n. 11. CORRÊA, R.L. 1994. "Territorialidade e corporação: um exemplo" In SANTOS, SOUZA e SILVEIRA (Orgs.) Território, globalização e fragmentação, São Paulo: Edit. Hucitec.

DODSON, B. e KILIAN, D. 2001. "De porto a playground - a revitalização da enseada de Victoria \& Alfred, Cidade do Cabo" (pp. 193-222), In: Tyler, D., Guerrier, Y. e Robertson, M. (Orgs.) Gestão de turismo municipal-teoria e prática de planejamento turístico nos centros urbanos, São Paulo: Edit. Futura.

FEATHERSTONE, Mike .1995. Cultura de consumo e pós-modernismo, Studio São Paulo: Nobel.

GUATTARI, F. 1985. "Espaço e poder: a criação de territórios na cidade" In Espaço \& Debates, Ano V, N.16.

HALL, Peter .2002 [1988]. Cidades do amanhã (Coleção Urbanismo), São Paulo: Editora Perspectiva. 
HARVEY, David .1992. Condição pós-moderna - uma pesquisa sobre as origens da mudança cultural, São Paulo: Edições Loyola.

.1996. "Do gerenciamento ao empresariamento: a transformação da administração urbana no capitalismo tardio" In: Espaço \& Debates (Cidades: estratégias gerenciais), Ano XVI, n.39 (pp.48-64).

JOLY, Carolina .2002. "O centro histórico de Campinas - refuncionalização social e preservação das edificações arquitetônicas”, Monografia de Graduação, Depto. de Geografia (IG/Unicamp), Campinas, São Paulo.

LEITE, Rogério P. 2004. Contra-usos da cidade - lugares e espaço público na experiência urbana contemporânea, Campinas: Editora Unicamp/UFS.

LUCHIARI, M. T. D. P. 1999. "O lugar no mundo contemporáneo - turismo e urbanização em Ubatuba (SP)" Tese de Doutorado, IFCH/Unicamp, Campinas, São Paulo.

MENESES, Ulpiano T. B. De. 1999. "Valor cultural, valor económico: encontros e desencontros", II Seminário Internacional de História da Energia, Fundação Patrimônio Histórico da Energia de São Paulo.

MINISTÉRIO DAS CIDADES .2004. "Política de reabilitação de áreas urbanas centrais" In: Cadernos Mcidades/Programas Urbanos - Planejamento territorial urbano e política fundiária - 3, Brasília, DF.

REIS FILHO, Nestor Goulart .2001. "Comentários" (pp.138-143) In: Os centros das cidades - reflexões e propostas para a cidade democrática do século XXI, São Paulo: Editora Terceiro Nome/Viva o Centro/Imprensa Oficial.

SÁNCHEZ, Fernanda .2003. A reinvenção das cidades - para um mercado mundial, Chapecó: Editora Argos.

SANTOS, Milton. 1965. A cidade nos países subdesenvolvidos, Rio de Janeiro: Ed. Civilização Brasileira.

.1996. A natureza do espaço - técnica e tempo, razão e emoção, São Paulo: Editora Hucitec.

.1999. "O território e o saber local: algumas categorias de análise" In Cadernos IPPUR, Ano XIII, N.2, Rio de Janeiro..

.2000. O papel ativo da geografia - um manifesto, Laboplan/Dpto. Geografia/USP, XII Encontro Nacional de Geógrafos (ENG), Florianópolis, S.C. SOUZA, Marcelo J.L. de (1995) "O território: sobre espaço e poder, autonomia e desenvolvimento" In: Castro, I.E. de, Gomes, P.C. da C. e Corrêa, R. L. (Orgs.) Geografia: conceitos e temas, Rio de Janeiro: Editora Bertrant Brasil.

VAINER, C. 2000. "Pátria, empresa e mercadoria - Notas sobre a estratégia exclusiva do Planejamento Estratégico Urbano" In: Arantes, Vainer e Maricato (Orgs.) $A$ cidade do pensamento único, Petrópolis: Edit. Vozes. 